\title{
Communication and Culture in Global Software Development: The Case of Mauritius and South Africa
}

\author{
Maureen Tanner \\ University of Cape Town, Cape Town, South Africa
}

\section{M.Tanner@uct.ac.za}

\begin{abstract}
Global Software Development (GSD) is a growing sector in Mauritius and South Africa. With an increasing number of information technology (IT) investors, both countries are being recognised as IT hubs in the Southern African region; hence the need for further research on GSD in those two countries. Furthermore, due to a highly diverse cultural setting prevailing in Mauritius and South Africa, common GSD practices derived from other studies might not be fully successful when applied in these contexts. It is thus useful to explore how alternative GSD practices have been put in place to handle these cultural disparities and the resulting communication requirements. The study has been undertaken in an attempt to enlighten investors on the communication and cultural practices that could be followed while partaking in GSD in Mauritius and South Africa.
\end{abstract}

Keywords: Global Software Development, Culture, Communication, Mauritius, South Africa, Communication Technology, Grounded Theory.

\section{Introduction}

Global Software Development (GSD) involves the development of application software through interactions of people, organizations, and technology across nations with different backgrounds, languages, and working styles (Herbsleb \& Mockus, 2003). GSD is enacted through virtual teams whose members transcend time, space, and culture and communicate through computer-mediated technologies (Jarvenpaa, \& Leidner, 1998). As Mohagheghi (2004) notes, IT outsourcing is one of the approaches to GSD. Organisations choose to outsource in order, inter alia, to take advantage of cost reduction, improve performance, and gain access to wider labour markets (Casey \& Richardson, 2006). Due to low labour costs in developing countries, more and more organisations are opting to contract with organisations from these regions. However, as Herbsleb and Moitra (2001) note, GSD is not easy to orchestrate, due mostly to cultural disparities and complex communication requirements of virtual

Material published as part of this publication, either on-line or in print, is copyrighted by the Informing Science Institute. Permission to make digital or paper copy of part or all of these works for personal or classroom use is granted without fee provided that the copies are not made or distributed for profit or commercial advantage AND that copies 1) bear this notice in full and 2) give the full citation on the first page. It is permissible to abstract these works so long as credit is given. To copy in all other cases or to republish or to post on a server or to redistribute to lists requires specific permission and payment of a fee. Contact 0HPublisher@InformingScience.org to request redistribution permission. teams.

The growth of outsourcing has been phenomenal. Indeed India is and is expected to remain the primary delivery location for IT outsourcing. However, recent trends have shown that new geographical locations are emerging as delivery time zones (Burton, 2009). Examples of emerging IT Outsourcing destinations in Africa include Mauritius 
(Burton, 2009) and South Africa (IT Match Online, 2008). Both countries are recognised as IT hubs in the Southern African region (Burton, 2009; Knight, 2006). The attraction of the two countries is that they offer cheap and highly skilled labour, as well good IT infrastructures (Burton, 2009; Knight, 2006). The increasing investment rate in the two countries necessitates the need for further research as a means to better inform the project planning and management decisions of international investors in the region. It is also interesting to note that Mauritius and South Africa are known to have diverse cultural heritage, as will be later discussed (Mauritius.Net, n.d.; "South African languages and culture," n.d.).

In spite of these developments, no GSD studies focusing on Mauritius and South Africa could be identified. It might thus be useful to explore how these cultural disparities and the resulting communication requirements are being handled in the two countries. Such knowledge might be useful to potential investors when establishing their plan of action for GSD projects as existing practices devised from more developed countries might not be entirely applicable to the Mauritian and South African contexts.

This study has been undertaken in an attempt to explore the intricacies of communication and cultural practices embraced within these two countries in the context of GSD. Both the offshore and the onshore perspective have been considered. The Mauritian case study offered the viewpoint for a culturally diverse offshore site as the main company, located in France, outsourced some of its software development to a company on the island. The South African case study offered the viewpoint for a culturally diverse onshore site as the local company outsourced some of its software development to a company in India. Data for the study was gathered through semistructured interviews with different stakeholders. The data was analysed using Grounded Theory analysis techniques. The results are part of a bigger study which covered several other aspects of GSD in South Africa and Mauritius. However, this article shall focus only on communication and culture aspects.

The paper is structured as follows. The next section describes the social context in which the study was undertaken. This is followed by an overview of the role of communication and culture in GSD. A synopsis of the research methodology is then provided followed by a description of the cases. The analysis of the results is then detailed in the data analysis section. A discussion of the key findings specific to the Mauritian and South African contexts is next provided. The conclusion then assesses the contribution of the research findings for both practitioners and the body of knowledge.

\section{The Social Context}

In order to appreciate the contextual issues prevailing in these two countries, this section will provide a brief overview of the outsourcing trend in Mauritius and South Africa.

\section{South Africa}

South Africa, also known as the "rainbow nation," consists of one of the most complex and culturally diverse populations in the world. Of the 49 million South Africans, $79.2 \%$ are African (Black), 9.2\% are White, 9\% are Coloured and 2.6\% are Indian/Asian (Statistics South Africa, 2008). The Black population is further divided into four major ethnic groups: namely, Nguni, Sotho, Shangaan-Tsonga, and Venda. On the other hand, the White population is of the Afrikaans (Dutch) (60\%) and British descent (40\%). There are also 11 official languages in South Africa (Explore South Africa, n.d.).

South Africans were governed by apartheid laws from 1984 to 1994. According to that legal system, people were classified into racial groups (White, Black, Indian, and Coloured) and separate geographic areas were created for each racial group ("Apartheid South Africa", n.d.). In April 
1994 the first multi-racial democratic elections were held and the apartheid regime was subsequently abolished. However, in spite of the elimination of the apartheid regime, the big gap between the haves and the have-nots based on racial lines still prevails in the country (Adato, Carter, \& May, 2004). Due to the diverse cultural heritage of South Africa, a study within this particular context could provide a different insight on the practices which are usually embraced by GSD companies.

South Africa is most commonly known as an offshore site. For instance, according to the Global Outsourcing Report, South Africa lies among the 20 best countries marked as "global opportunity" for IT offshore investment and is predicted to rise to the 15th place by 2015 (Minevich \& Richter, 2005). However, South Africa can also be considered as an onshore site as the outsourcing trend of South African companies to other countries has also been rising exponentially. For instance, according to a Xerox survey undertaken in 2000, 94\% of South African companies were outsourcing their operations (Nothard, 2000). This demonstrates a high interest in GSD within South Africa and justifies the need for research in that context. For the purpose of this study, South Africa will be studied from the perspective of an onshore site, whereby a local company chose to outsource its software development to India.

\section{Mauritius}

Mauritius is located in the South West Indian Ocean. The population of this island of 720 square miles comprises a medley of all races, ethnic backgrounds, and cultures and is in many ways a living reflection of East meeting West (Mauritius.net, n.d.). The population ethnicity consists of Indo-Mauritians (68\%), Creoles (27\%), Sino-Mauritian which are of Chinese descent (3\%), and Franco-Mauritians (2\%). Mauritius is also a bilingual country with English as the official language. French dominates the public life but is, however, not an official language. Both English and French are compulsory languages, which are learnt as from primary school (The World Factbook, n.d.). The English and French language proficiency prevailing in Mauritius originates from the past French $(1715-1810)$ and British $(1810-1968)$ colonial establishments on the island. Mauritius obtained independence from the British in March 1968 (InfoPlease, n.d.).

Mauritius is an attractive outsourcing destination. The Government of Mauritius has undertaken to transform the island into a Cyber island and develop Information and Communication Technology (ICT) as the 5th pillar of the economy alongside sugar, textile, tourism, and financial services (Burton, 2009). Between October 2006 and March 2007, 41 international ICT players started operating in Mauritius. These included Oracle, Microsoft, IBM, HP, CISCO, Accenture, Infosys, Hinduha Group, France Telecom, Teleforma, and TNT group (Burton, 2009).

By investing in the island, those ICT players seek to take advantage of the regulated jurisdiction in place on the island. For instance, a few administrative relaxations have been effected and certain provisions of the domestic laws have been waived as a means to provide incentives to offshore investors. Several acts have been put in place including the Electronic Transaction Act, the Data Protection Act, and the Cybercrime and the Computer Misuse Act (Jaddoo, 2009). ICT players also invested in Mauritius as the island offers state-of-the-art telecommunications, a quality IT infrastructure, and favourable time zone of GMT +4 , which are important backbones for successful offshore setups (Tradersafrica, n.d.). For the purpose of this study, Mauritius will be studied as an offshore site.

\section{Communication and Culture in GSD}

The role of communication and Culture in GSD will be discussed in the following sections. 


\section{Communication}

Communication, particularly informal communication, plays a critical role in virtual teams and GSD projects (Herbsleb \& Mockus, 2003), and barriers hindering communication flow are numerous (Perry, Staudenmayer, \& Votta, 1994; Prikladnicki, Audy, \& Evaristo, 2003). These challenges relate to the lack of unplanned encounters among the developers, the cost of initial contact, the inability to communicate effectively, and the lack of trust and willingness to communicate effectively (Herbsleb \& Mockus, 2003).

Various practices have been proposed to mitigate these challenges (Damien, 2002). For instance, communication issues are handled through regular meetings, which can either be ad-hoc or planned, or organised through weekly video-conference sessions (Paasivaara \& Lassenius, 2004). These regular encounters improve the team's project definition (Ramesh \& Dennis, 2002), foster socialisation, trust, respect among team members (Maznevski \& Chudoba, 2000), and enhance subsequent electronic communication (Paasivaara, 2003). Individuals with outgoing personalities are also sent as ambassadors and are given the explicit task of meeting people in a variety of groups at the other sites. These face-to-face meetings are crucial, especially in the beginning of projects, as they leverage the chances of having urgent and important questions answered (Paasivaara, 2003).

Teams also collaborate by using various communication tools, ranging from telephone calls (Hindus, Ackerman, Mainwaring, \& Starr, 1996), fax, chat (Handel \& Herbsleb, 2002), instant messaging (Nardi, Whittaker, \& Bradner, 2000), video conference (Dourish \& Bly, 1992; Fish, Kraut, \& Root, 1992; Obata \& Sasaki, 1998), email, and groupware applications (Majchrak, Rice, King, Malhotra, \& Ba, 2000; Maznevski \& Chudoba, 2000). These practices are used to support the four communication needs of GSD: namely, problem solving, informing and monitoring, relationship building, and decision-making and coordination (Paasivaara, 2003). However, their success is limited, and they face challenges like poor design that does not facilitate adoption (Shami, Bos, Wright, Hoch, Kuan, Olson, \& Olson, 2004). Furthermore, the synchronicity of the communication tools is of no use in some cases. For instance, if in spite of the tools' availability, individuals forget to communicate changes and updates made during the day to other dispersed team members (Prikladnicki et al, 2003), it results in repeated work and time wastage (Ramesh \& Dennis, 2002).

It might be interesting to understand the extent to which such practices are followed in Mauritius and South Africa and whether new ones have been devised to fit these contexts. In order to do so, it is, however, important to understand the intricacies behind the communication process. Hence, parsing patterns and the shared experience, which are important components of the communication process, are detailed below.

\section{Parsing Patterns and the Shared Experience}

While living through various experiences, individuals tend to chop events into separate meaningful chunks, which are then stored for later retrieval. This process is known as parsing (Cockburn, 2002). Individuals tend to parse experiences using different patterns, based on cultural or political values, among others. This produces different information chunks that vary from person to person, each representing a unique perception of the experience. Attempting to combine these information chunks provide a distorted, simplified, and incomplete version of the experience. This suggests that communication is determined by experience and language skills and that the phenomenon of communication does not depend on what is transmitted but on what happens to the person who receives it (Maturana \& Varela, 1998).

People generally know that their intended message is correctly passed on to the listener according to the feedback obtained from the latter. However, these return messages can be misinterpreted, 
leading the communicator to falsely conclude that the message is understood. In such cases, a common experience to refer to, among the sender and the recipient, can decrease the risk of misunderstanding and leverage the chances of having successful communication (Cockburn, 2002). The shared experience is an important missing factor in GSD as individuals are less likely to have participated in the same projects (Mockus \& Herbsleb, 2001). Consequently, there is a higher risk of having incomplete or incorrect information being passed among team members. This leads to a higher probability of misunderstanding and communication failures.

The importance of the shared context has also been highlighted by Kogut and Meitu (2000) in relation to product requirements elicitation and in the case of creative tasks. Communication is never a perfect and complete process. According to Cockburn (2002), "People don't even know what it is that they wish to communicate." Even if they did, recipients always have to bridge a gap at some point. In globally distributed teams, the situation is often worsened by the fact that members come from different cultures. As such, they are fundamentally different from each other, and the greater the difference, the smaller the possibility of bridging the gap.

\section{Culture}

Cultural issues prevail due to the fundamental differences in values governing people's lives. Based on their culture, individuals have different attitudes towards communication styles and preferences and behaviours (Perry et al., 1994; Prikladnicki et al., 2003). It is the boundary condition for all personal communication (Gudykunst, \& Matsumoto, 1996).

For instance, communication styles and preferences are characterised by the different ways in which people express agreements and disagreements or ask questions. Different behaviours can be perceived when acknowledgement by one person is sometimes mistaken for agreement by someone else (Herbsleb, Paulish, \& Bass, 2005). Differences in behaviours are also felt in how individuals categorise things, what decision procedures they use, and the basis on which they evaluate themselves (Fiske, Kitayama, Markus, \& Nisbett, 1998).

Cultural differences have a "negative" impact on communication (Van Ryssen \& Hayes-Godar, 2000) causing people to decipher communication through their own cultural perspective. Studies have also demonstrated that an awareness and understanding of these differences, through previous cultural exposure, helps to alleviate these misunderstandings (Jarvenpaa \& Leidner, 1999; Kayworth \& Leidner, 2000; Sarker \& Sahay, 2002). Interestingly, two studies have contradicted these findings (Kiel, 2003; Krutchen, 2004), whereby despite being aware of their cultural disparities, team members still felt frustrated and communication was not very effective. This leaves room for further research to really understand consequences of cultural disparities within GSD and what coping strategies would be more appropriate.

Since individuals in virtual teams often belong to differing cultures (Jarvenpaa \& Leidner, 1999), the need to address these challenges is therefore strong so as to enhance GSD project success (Kayworth \& Leidner, 2000). The different cultural awareness practices followed by GSD companies are detailed in Table 1.

Table 1 - Cultural Awareness Practices

\section{Cultural Awareness Practices}

Intercultural training programs (Kayworth \& Leidner, 2000; Sarker \& Sahay, 2002)

Cultural liaisons / representatives (Carmel \& Agarwal, 2001)

Technical or managerial liaisons / representatives (Heeks, Krishna, Nicholsen, \& Sahay, 2001) 
Intercultural training programs increase the awareness of the team members on the different cultures prevailing in the team and the expected behavioural patterns of the dispersed team members. Cultural liaisons and managerial representatives present at the different sites are meant to clarify any misunderstandings that might occur due to cultural differences.

The next section details the methodology employed for this study.

\section{Methodology}

The research approach adopted for this study was interpretive, qualitative, and empirical in nature. The approach was appropriate as it allowed for an understanding of the context as well as "the process whereby the information systems influences and is influenced by the context" (Walsham, 2002). As GSD is broad and complex and may be difficult to be studied outside the context within which it occurs, case studies were useful.

Two case studies were drawn from Mauritius and South Africa respectively. For each case, the situation in specific dispersed teams was studied and the communication and cultural practices were uncovered. As the purpose of the research was to a generate theory applicable to various organisational contexts, differences in organisational conditions were sought. These differences relate to the interviewee role, the offshore and onshore sites, the software development method employed, and the communication technology employed. This allowed for generalisation and maximum application of information to other cases (Patton, 2002). The differences in the chosen case studies are outlined in Table 2 .

Table 2 - Characteristics of the Mauritian and South African Case Studies

\begin{tabular}{|l|l|l|l|l|l|}
\hline $\begin{array}{l}\text { Case } \\
\text { No }\end{array}$ & Interviewee Role & Offshore site & Onshore site & $\begin{array}{l}\text { Software } \\
\text { Development } \\
\text { method }\end{array}$ & $\begin{array}{l}\text { Communication } \\
\text { Technology }\end{array}$ \\
\hline Case 1 & $\begin{array}{l}\text { Software Developer } \\
\text { Team Leader }\end{array}$ & Mauritius & France & $\begin{array}{l}\text { Adapted } \\
\text { Waterfall } \\
\text { /Prototyping }\end{array}$ & $\begin{array}{l}\text { Video conference } \\
\text { Email } \\
\text { Phone } \\
\text { Remote Desktop } \\
\text { Sharing }\end{array}$ \\
\hline Case 2 & $\begin{array}{l}\text { Team Leader } \\
\text { Software Developer } \\
\text { Analyst }\end{array}$ & India & South Africa & Waterfall & Video Conference \\
\hline
\end{tabular}

\section{Data Collection}

Semi-structured interviews were the primary source of information as these allowed the researcher to access the participants' interpretation regarding actions or events (Walsham, 2002). The interviews remained open-ended and assumed a conversational manner. Each respondent was interviewed for one hour and a total of 13 interviews were conducted during the course of this study (six from the Mauritian case, seven from the South African case). All the interviews were conducted in Mauritius and South Africa respectively, but also included interviews of foreign delegates/team members present at these respective sites at the time. The opinion of team members from foreign sites (France in Case 1 and India in Case 2) was, therefore, also obtained.

A maximum variation sampling strategy was chosen. Such a strategy allowed the investigator to obtain the broadest range of information and perspectives on the subject of study, namely GSD (Guba \& Lincoln, 1989). During the interviews, questions were asked pertaining to how GSD was being practiced in the organisations from a communication and cultural perspective in order to overcome GSD issues. 


\section{Data Analysis}

The grounded theory techniques (Strauss \& Corbin, 1998) were used for analysis purposes during the course of this study. As required by the grounded theory techniques, there should be continuous interplay between data collection and analysis (Myers \& Avison, 2002). Through this iterative approach, data analysis was performed in parallel to data collection, and the results of the analysis informed and directed the data collection process. Data collected in this study was analysed using open coding, axial coding, and selective coding (Strauss \& Corbin, 1998).

The general idea behind open coding was to generate a list of concepts which were then grouped into categories. As concepts were the basic building blocks of the theory, the first task in developing them was to open the data and reveal the name of these concepts (Strauss \& Corbin, 1998, as cited in Brown, 2005). This was achieved through constant comparative analysis by comparing similarities and differences between data incidents. Discrete concepts were then produced and labelled (Strauss \& Corbin, 1998). Comparisons were also made as a means to develop a common name for multiple observations of data incidents (Locke, 2001). A sample open coding sheet is given in Appendix 1.

Axial coding is defined as "the process of relating categories to their sub-categories, termed 'axial' because coding occurs around the axis of a category, linking categories at the level of properties and dimensions" (Strauss \& Corbin, 1998). During axial coding, statements from the interview transcripts were analysed to uncover relationships among the concepts which were grouped into categories. Each relationship was given a specific code name. Initially during the coding process, each relationship identified from each statement was individually drawn and labelled on paper. All related concepts and their corresponding relationships were then regrouped on a big mind map at the end of one case study analysis. This mind map proved to be a useful research instrument, allowing the researcher to visualise how the concepts were related to each other. It also helped in forming preliminary research outcomes and to answer the research questions. After the creation of the first mind map, the researcher proceeded to the analysis of the next case study. These allowed for new concepts and relationships to be uncovered, and the validation of both the existing categories and relationships. A sample axial coding sheet is given in Appendix 2.

The quote and the interview question provided only a simplistic view of the raw data on which the study was based. The relationships instead emerged through the analysis of many different contextual elements. Paragraphs from the body of text were studied in an attempt to make sense of the different concepts and categories and their respective relationships.

Selective coding involved identifying the core category and trimming away excess categories not strongly linked to the core category (Strauss \& Corbin, 1998). The first attempt at selective coding following the analysis of the second case study produced 15 high level concepts, regrouped in seven categories. However, as the analysis process continued, these categories and concepts gradually evolved and produced the final set of categories as described in the results and analysis section.

Categories and their relationships were refined in two stages, namely, at the concept level and at the relationship level. Refinement at the concept level was undertaken throughout the whole analysis process. Based on evidence in the data, some categories gradually evolved into more abstract ones, which better described the phenomenon under study. Eventually, once the concept hierarchy reached a stable state, the core category was selected. All the high-level categories surrounding that core concept were then organised around the core category, so as to represent the essence of the phenomenon under study. Refining at the relationship level was done according to Strauss and Corbin's (1998) recommendation: “... findings should be presented as a set of interrelated concepts, not just a list of themes." Therefore, all categories that did not participate in a relationship were trimmed, and those which did not contribute to the theory, in spite of being linked to- 
gether, were discarded. Lastly, the properties were categorised based on the number of relationships they participated in and the number of times the properties occurred in the data. Those with high occurrences and participation in relevant relationships were isolated and used to create the story line (Strauss \& Corbin, 1998).

\section{Theoretical Saturation}

In line with Coetsee (2006), theoretical saturation was demonstrated through the use of Figure 1, which shows the number of concepts coded per interview and also the number of relationships revealed per interview coded. As can be seen in the graph, the number of concepts identified did not increase as analysis progressed. The number even slightly decreased. This is because more effort was eventually placed towards creating and identifying properties and relationships (i.e., axial coding) as opposed to identifying new concepts. For instance, upon reaching interviews 12 and 13 , both the number of concepts and the number of relationships dropped, indicating that a saturation point was reached.

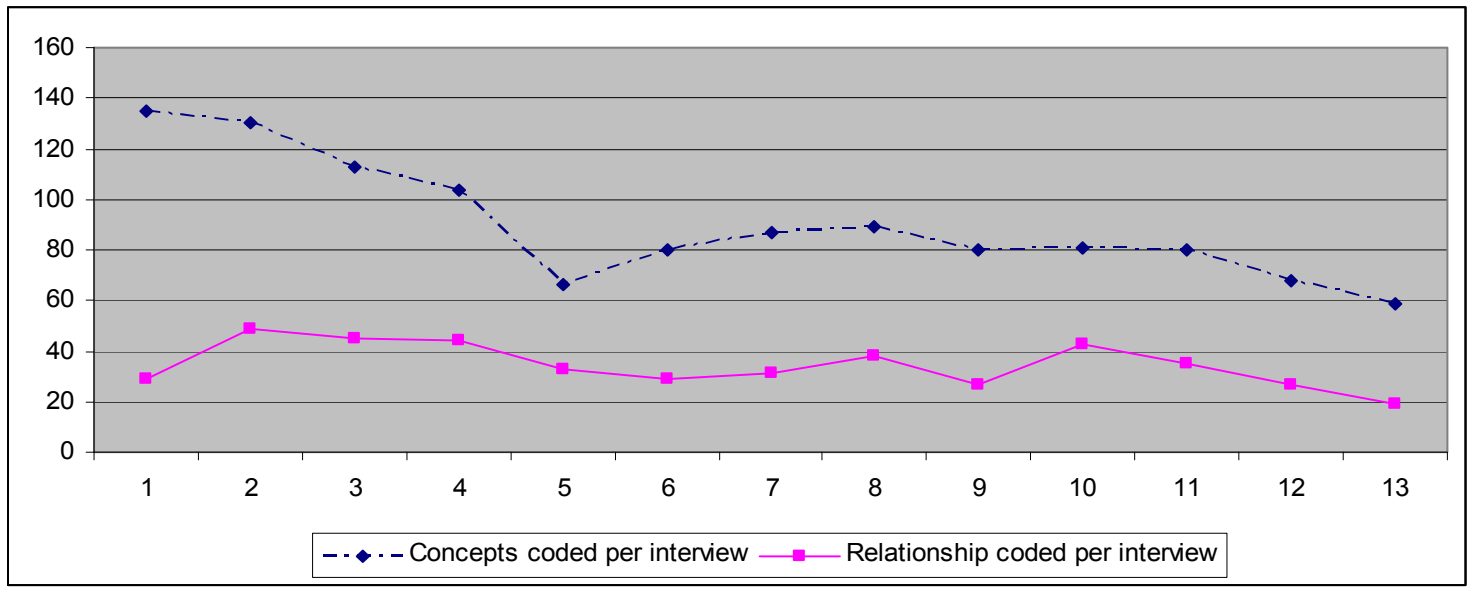

Figure 1 - Number of Concepts and Relationships from Coding Process

\section{Sample}

The sample in this study consisted of IT professionals from companies located in two countriesMauritius and South Africa-providing research data for two cases. Each is discussed in turn.

\section{CASE 1 - Mauritius}

Case 1 (C1) was conducted in an organisation having branches in France (Paris and Toulouse) and in Mauritius that provided software for the French retail sector. The Mauritian branch was involved in the development of application software for both the company's internal use and for external customers. The work was subcontracted by the company in France and mostly involved the migration of the legacy software from VB6 to VB 2005. The Mauritian branch also provided support and development work on the customer relationship management (CRM) system, the data warehousing software, the project management application, the time keeping application, as well as the main software applications deployed at the customers' sites.

The Mauritian branch was composed of five software development teams and four migration teams. As summarised in Table 3, interviews were conducted on team members from both migration and software development teams as well as a delegate from Paris. Composed of three members, the first team (T1) handled the internal products of the company. Interview 1 was conducted on a software developer from team T1. The second team (T2) was composed of four members 
and was responsible for migration work from VB6.0 to VB2005. Interview 2 was conducted on a software developer from T2. The third team (T3) was composed of four members and collaborated with both the Paris and Toulouse teams. They were responsible for both migration and development work on the main applications. Interview 3 was conducted on the team leader and interview four on one software developer of T3. The fourth team (T4) was composed of three team members responsible for developing applications for customer relationship management, project management, and time keeping. Interview 5 was conducted on the team leader of T4. Finally, interview 6 was conducted on a delegate from France.

Table 3 - Case Study 1 Sample

\begin{tabular}{|l|l|l|}
\hline Interview No & Team & Position \\
\hline 1 & T1 & Software Developer \\
\hline 2 & T2 & Software Developer \\
\hline 3 & T3 & Team Leader \\
\hline 4 & T3 & Software Developer \\
\hline 5 & T4 & Team Leader \\
\hline 6 & Paris & Onshore Delegate \\
\hline
\end{tabular}

\section{CASE 2- South Africa}

Case 2 (C2) was conducted in the IT department of a South African Insurance company. The IT department was involved in the development and maintenance of call centre applications, commission maintenance applications, and online share trading applications. Similarly to other insurance companies worldwide, $\mathrm{C} 2$ previously invested in COBOL and assembly legacy applications. At the time of the study, the department was involved in the migration of these applications towards service oriented architecture. The project investigated during the case study was the commission maintenance system. Originally written in Cobol 35 years ago, it calculated the amount of commission to be paid to the brokers. The new application was being developed in Java.

The development of this application was outsourced to a vender called TCS. TCS was an Indian company ranked at number 3 worldwide from an offshore vendor perspective. This vendor was selected due to its experience in the development of a similar application for an Australian insurance company. The team consisted of two systems analysts, one business analyst, five developers, and two testers. Two of the five developers were from the South African team (SAT) while the others were from TCS. The business analyst was from SAT while each systems analyst belonged to SAT and TCS respectively. The same applied for the two testers. The major differences among the SAT and the TCS resources lay in their basic qualifications and the number years of work experience. The TCS resources were mostly engineers, while those from SAT were only high school graduates. TCS resources had on average three years of work experience and were on average 24 years of age, while the SAT resources had about 20 years of experience and were on average 38 years of age. Sample characteristics of C2 are summarised in Table 4. 
Table 4 - Case Study 2 Sample

\begin{tabular}{|l|l|l|}
\hline Interview No & Position & Team \\
\hline 1 & Project Manager & 1 \\
\hline 2 & Software Developer & 1 \\
\hline 3 & Tester & 1 \\
\hline 4 & Tester & 1 \\
\hline 5 & Business Analyst & 1 \\
\hline 6 & Software Developer & Offshore delegate \\
\hline 7 & Software Developer & Offshore delegate \\
\hline
\end{tabular}

The cases chosen for this study comprised different cultural settings, with different history, work processes and the level of experiences in GSD. Each team employed various forms of work processes, software development methods, and communication practices. This, therefore, laid ground for rich responses from each of the participants of the study.

\section{Data Analysis}

This section describes the results from the coding process as well as the high level categories selected for inclusion.

\section{Results from Open Coding}

During the open coding process, data represented by interview transcripts was examined in order to identify as many concepts as possible. Related concepts were regrouped into categories, thus achieving a proper level of abstraction and limiting the number of concepts the researcher had to work with (Strauss \& Corbin, 1998). The names chosen for the concepts and categories were chosen in such a way that the researcher was quickly reminded of its referent (Strauss \& Corbin, 1998). A total of 238 concepts were identified in the study and 177 were considered relevant (as discussed in the selective coding section). In order to limit the amount of information being dealt with and to maintain some level of focus on the research questions, these concepts were organised into higher-level categories.

The final hierarchy list consists of seven meta-categories and 28 categories. Categories were developed by identifying "properties" that defined them. Categories with many properties were considered as being theoretically rich and apt to describe the phenomenon under study. Table 5 provides a description of the meta-categories selected for the final theory. A description of each category is provided as well as the number of properties, the number of out links, and the number of in links for each of them. Appendix 3 provides the complete property description of the main categories relevant to this paper namely communication practices, culture, and technology. 
Table 5 - Meta Category Description

\begin{tabular}{|c|c|c|c|c|}
\hline $\begin{array}{c}\text { Meta - } \\
\text { Category }\end{array}$ & Description & $\begin{array}{c}\text { No of } \\
\text { properties }\end{array}$ & $\begin{array}{l}\text { No of } \\
\text { out } \\
\text { links }\end{array}$ & $\begin{array}{l}\text { No of } \\
\text { in links }\end{array}$ \\
\hline $\begin{array}{l}\text { Communica- } \\
\text { tion Practices }\end{array}$ & $\begin{array}{l}\text { Communication Practices describe how the communi- } \\
\text { cation process was usually undertaken within two cas- } \\
\text { es. This category encompasses details of the communi- } \\
\text { cation process, the communication channel description, } \\
\text { communication facilitators, communication strategies } \\
\text { in place within the organisation, and the level of cues } \\
\text { being transmitted during the communication process. } \\
\text { The communication channel description relates to the } \\
\text { communication affiliation (either dry and impersonal or } \\
\text { warm), the communication level (either minimal or } \\
\text { constant), the communication style (either informal or } \\
\text { business style), the news type (either good or bad) and } \\
\text { the type of information being filtered through (either } \\
\text { wrong info or correct info). }\end{array}$ & 19 & 14 & 11 \\
\hline Culture & $\begin{array}{l}\text { Culture can be seen as an external factor which impacts } \\
\text { on Communication Practices within the organisation. It } \\
\text { encompasses the national culture, organisational cul- } \\
\text { ture, the team culture, and the individual culture or per- } \\
\text { sonality. } \\
\text { The culture meta-category also represents the level of } \\
\text { cultural differences among people. }\end{array}$ & 6 & 6 & 2 \\
\hline $\begin{array}{l}\text { GSD Process } \\
\text { Issues }\end{array}$ & $\begin{array}{l}\text { The GSD Process Issues category refers to communica- } \\
\text { tion, coordination, and software development issues } \\
\text { encountered within GSD. }\end{array}$ & 24 & 11 & 21 \\
\hline GSD Project & $\begin{array}{l}\text { The GSD Project category describes a GSD project in } \\
\text { terms of the project size, the project importance, the } \\
\text { number of hours attributed to it, and the work type, } \\
\text { among others. } \\
\text { It also encompasses information about what contributes } \\
\text { to GSD project success, examples of which are the pro- } \\
\text { ductivity level, the project delivery speed, the quality, } \\
\text { and the software development precision achieved. }\end{array}$ & 17 & 15 & 5 \\
\hline GSD Team & $\begin{array}{l}\text { For GSD to be a success, the GSD team should be } \\
\text { composed of individuals with key characteristics. The } \\
\text { GSD Team category describes the characteristics of a } \\
\text { GSD team based on the team members' experience } \\
\text { level, their expertise, their specific characteristics, the } \\
\text { team recruitment management process, and the ideal } \\
\text { team structure. }\end{array}$ & 27 & 19 & 9 \\
\hline
\end{tabular}




\begin{tabular}{|c|c|c|c|c|}
\hline $\begin{array}{c}\text { Meta - } \\
\text { Category }\end{array}$ & Description & $\begin{array}{c}\text { No of } \\
\text { properties }\end{array}$ & $\begin{array}{c}\text { No of } \\
\text { out } \\
\text { links }\end{array}$ & $\begin{array}{l}\text { No of } \\
\text { in links }\end{array}$ \\
\hline $\begin{array}{l}\text { GSD Value } \\
\text { Issues }\end{array}$ & $\begin{array}{l}\text { GSD Value Issues are issues that occurred on a more } \\
\text { individual and emotional level within GSD. This cate- } \\
\text { gory encompasses GSD trust issues, missing visual } \\
\text { cues, uncertainty issues, and work interaction issues. } \\
\text { GSD Value issues also occur within the GSD Project } \\
\text { context and arise due to the emotional differences } \\
\text { among the individuals. }\end{array}$ & 7 & 3 & 6 \\
\hline Technology & $\begin{array}{l}\text { Technology impacts on communication practices, GSD } \\
\text { process issues, GSD project, GSD team, GSD value } \\
\text { issues, and on technology itself. In this study, a wide } \\
\text { range of technologies are available to be used during } \\
\text { GSD, including chat, email, Net Meeting, phone, con- } \\
\text { ference calls, and video conference. Each of these is } \\
\text { effective when used for the right task and in the right } \\
\text { context. Some can be used to overcome the disadvan- } \\
\text { tages introduced by others. Furthermore, each of the } \\
\text { organisations seemed to have some level of preference } \\
\text { for one particular technology, based on their particular } \\
\text { communication and cultural needs. }\end{array}$ & 14 & 9 & 6 \\
\hline
\end{tabular}

\section{Results from Axial Coding}

This section introduces the axial links between the meta-categories. The relationships between these categories are described as a means to provide a more animated description of each phenomenon. Each category may serve as causal condition, intervening condition, action/interaction, or a consequence (Strauss \& Corbin, 1998). The results relate to both case studies. Differences and similarities across sites will be described in the discussion section.

\section{Links from communication practices to communication practices}

It was noted that it was hard for team members to have a proper perception of efforts put into the project due to the lack of physical proximity during GSD. Meetings where dispersed team members met in person facilitated the contact initiation and helped to bridge physical distance among the team members. Proper planning prior to any meeting also facilitated the contact initiation and was crucial for successful communication when three or more people were involved in the interaction process.

Team-customer communication strategies were also used to overcome communication issues among dispersed team members. For instance, by restricting communication between only some levels of management (e.g. team leaders and project managers), dispersed teams avoided communication issues.

Language interpretation issues were bridged by posting a professional liaison (foreign worker from the onshore site) at the offshore site. The offshore teams then learnt to speak the foreign language, thus facilitating the communication process. Good communication level was maintained through the implementation of flexi-time. 


\section{Links from communication practices to GSD process issues}

Communication problems were avoided through the adoption of a formal and professional communication style. Such was the case because a communication style involving a high amount of jargon introduced foreign language issues.

Constant communication was used to handle, manage, and avoid GSD Project delays. It allowed every stakeholder to be aware of any existing or potential issues, thus leaving room for necessary actions to be undertaken to handle and avoid the problems. Constant communication between the developers and the team leaders was also crucial to avoid deadline issues.

A team-customer communication strategy whereby only team leaders offshore were allowed to communicate with people at other sites was used to minimise the negative impact of time difference across the sites. In the absence of direct interaction, developers were only concerned with their work and were thus not affected by the time difference while communicating. Such a strategy overcame major communication issues as the number of people who were allowed to communicate was limited. By only allowing the team leaders to contact the project managers onshore, coordination issues were avoided as more control was put in place. However, whenever the team leaders were not available to act as communication liaison between the dispersed sites, coordination issues were introduced while applying such a communication scheme.

\section{Links from communication practices to GSD project}

If the team members had little or no perception of effort made by their fellow foreign team members, the project visibility was reduced. In addition, project visibility was also reduced by only allowing a certain category of team members (e.g. team leaders and project managers) to communicate with the clients or fellow dispersed workers. Such project visibility was however enhanced through a high level of reassurance concerning the work progress, proper planning prior to any communication (e.g. conference calls), and emails sent and responded to in due time.

\section{Links from communication practices to GSD team}

GSD participants were chosen for international meetings according to their job titles. For instance, developers rarely met foreign project managers or customers. Such physical encounters helped to improve the affiliation level among the team members. By having a foreign worker (from the onshore site) established offshore, the adaptability level of the resources was also promoted. It encouraged people to communicate by adapting to the culture of the foreign worker.

\section{Links from communication practices to GSD value issues}

In the absence of frequent physical encounters between the dispersed team members, the amount of visual cues conveyed during subsequent conversations was reduced. The negative impact of having limited visual cues conveyed during a conversation was compounded by the type of news being conveyed. As such, bad news was communicated with as many visual cues as possible.

When team members mutually reassured themselves about work progress during the course of a project, trust level was promoted. This was accomplished through regular phone calls to provide feedback about the whole project evolution.

\section{Links from communication practices to culture}

When employees did not work in the same office, the amount of physical encounters between them was limited. This further mitigated the cultural difference impact. Employees having no contact with foreign team members were unable to describe the foreign culture and did not feel any cultural difference. A formal and professional communication style was also used to over- 
come negative cultural influences. By maintaining a professional tone of voice, work was more efficiently performed.

\section{Links from technology to communication practices}

A good infrastructure setup for communication, in terms of phone lines, communal mail boxes, etc., helped to bridge geographical distance and facilitated the communication process. There were also different communication needs at different project phases, and different communication technologies were used to cater for these needs. For instance, the video conference was used during analysis. The phone was used to inform about the problems being encountered. The mail was used to communicate with the project managers.

\section{Links from technology to GSD process issues}

A wide range of communication technologies (email, chat, video conference, net meeting application, conference calls, phone) were used to alleviate GSD process issues. For instance, when requirements were unclear or when the terms used to describe the requirements were not clear, email and video conference were used to probe for further clarifications. Email was used to request confirmation when the language accent was too strong and prevented the message from being understood. Email was also of assistance during the scheduling of meetings in the proper time zones. Technologies like chat, which did not require the team members to verbally communicate, were used to overcome language accent issues.

However, poor technological support also hindered the communication process. Bandwidth limitation introduced communication delays as it reduced the usage efficiency of the communication tool. Inefficient phone lines introduced communication issues and communication delays as the phone calls were longer than necessary. Slow connection speed also introduced GSD project delays as the work process was slowed down and tasks were not completed on time, especially in urgent situations. Jumbled up emails introduced coordination issues and delays during communication because of low cue transmission level.

\section{Links from technology to GSD project}

Conference calls were employed to support general GSD work forms and project management tools helped to provide project visibility. However, connection speed caused some tools, like remote desktop sharing, to be inappropriate and ineffective in conducting GSD project work.

\section{Links from technology to technology}

The communication tools were selected based on the extent to which they suited the dispersed teams' communication requirements. For instance, the connection speed impacted on the choice of using video conference or not and enhanced the disadvantages of the communication tools like remote desktop sharing and emails. One technology was used to overcome the disadvantages conveyed by others. For instance, when the message is not properly expressed by email, the phone was used.

\section{Links from culture to communication practices}

The team culture determined whether employees were allowed to contact external customers or not. For instance, in teams having an informal arrangement with the customers (which describes their flat hierarchical structure), team members were allowed to contact external customers.

The national culture governed the communication style employed by the team members. This communication style could be diplomatic, straight forward, and even untactful. It also impacted on the level of collaboration across the sites since, based on their culture, some individuals were 
more willing to help than others. National culture drove the team-customer communication strategy. For instance, sites sharing a strong sense of hierarchy in their organisational structure did not allow the developers to communicate with the project managers. The team members respected this hierarchy even during the communication process.

\section{Results from selective coding}

The selective coding process was the final stage of the analysis process. It was however not conducted in isolation but rather in parallel with open and axial coding and both at the concept and relationship level. The set of categories to be included in the theory were gradually uncovered and those properties having no relationships to other properties were discarded.

Two main methods were employed to identify the properties having greater theoretical relevance. In the first instance, the number of links to and from a specific property was counted. The number of occurrences of the property in the interview was also counted. Properties with highest number of links and occurrences were considered to be more theoretically relevant or as being of high concern to the respondents. Properties with no links or little amount of occurrences were discarded. Properties could have a high amount of occurrences but without any links (Strauss \& Corbin, 1998). However, those having several axial links were generally interdependent. This implies that properties with high amount of links generally had high amount of occurrences. After several iterations through open coding, axial coding and selective coding, the final model outlined in Figure 2 eventually emerged. The resulting relationship diagram is described and discussed in the following section.

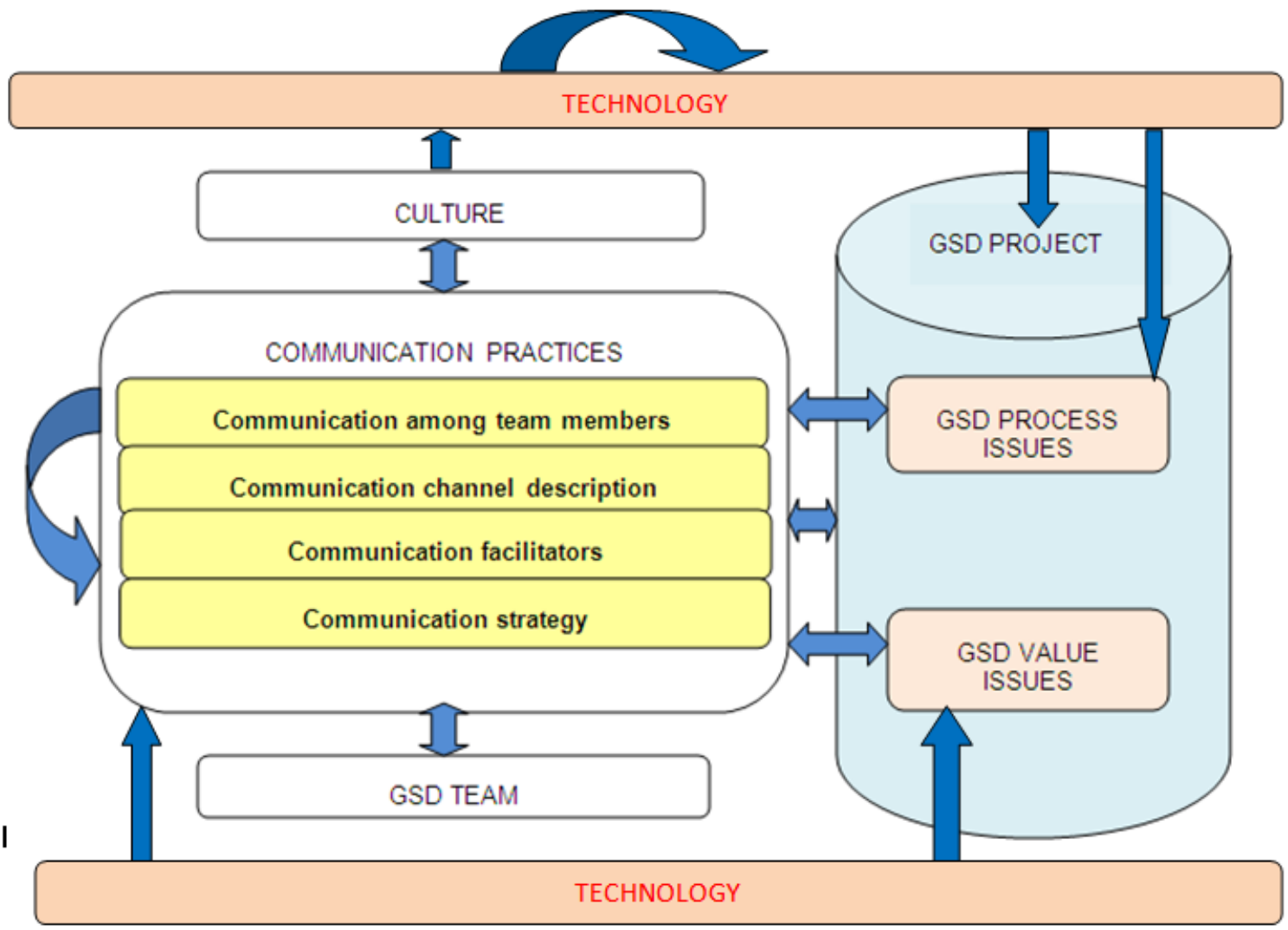

Figure 2 - Final Research Model 


\section{Findings}

The results presented in this paper are part of a bigger study which covered several other aspects of GSD in South Africa and Mauritius, hence the complex final model presented in Figure 2. However, as this paper solely focuses on the communication (including technology) culture, the discussion will only be centred on these variables.

\section{Communication Practices}

Communication is a major challenge faced by GSD companies (Herbsleb \& Grinter, 1999), and the two South African and Mauritian companies studied are no exceptions. In essence, the study reveals that effective communication practices have been devised to overcome communication issues (GSD Process Issues) in these particular contexts. Some of these practices are in line with those that have already been prescribed in past studies including international meetings, communication planning, and methods to ease initial contact (e.g. Herbsleb \& Grinter, 1999; Herbsleb, Zubrow, Goldenson, Hayes, \& Paulk, 2003; Maznevski \& Chudoba, 2000; Paasivaara \& Lassenius, 2004). One of the communication practices, however, does not seem to corroborate with what was mentioned in the literature.

In essence, past GSD studies reported that a high level of communication should be maintained across all sites and participants should communicate across all the sites and job titles (e.g. Robillard \& Robillard, 2000; Seaman, 1996). But what was observed in the two case studies does not support this communication practice. It appears that even with limited communication across all job titles and across all sites, GSD projects can be successful. Communication should instead be coordinated by one key person at one site, whose role is to pass on queries and issues to the other site and to obtain answers from them. In Mauritius, the team leader was responsible for coordinating the communication process across the sites as was explained by one of the respondents:

"We don't deal with them [The French team]. We ask our team leader and he will talk to them. He will talk to the French guys and they will sort out a solution".

The South African team members also contacted their Indian colleagues through the team leader:

"There was a team leader whom we contacted. It wasn't the analyst or the developer, we worked with the team lead".

The use of a key communication liaison at each site did not seem to hinder the communication flow in any major way in both the Mauritian and South African case studies. Instead, this communication method can be used as a way to leverage coordination issues and to control and monitor agreements being made between the different stakeholders across the sites. For instance it was mentioned by the team leader in one of the Mauritian interviews (offshore site) that:

"...if a developer just calls and agrees on something with the project leader in France and I am [team leader] not aware of it, there will be chaos. It is just for controlling what is going on".

A similar comment was made by a developer at the South African site (onshore site), whereby:

"...the key person will make sure that communication is going the right way. We need coordination and we need to ensure that no one goes into irrelevant details while communicating offshore. It's not supposed to be so".

This implies that both the offshore and the onshore site should share the same vision about the need for coordination through controlled communication process for this particular practice to be a success. 
The usefulness of this communication practice can be further validated by the introduction of delays within the GSD project in the absence of the key communication liaison. For instance, in the Mauritian site, one interviewee reported on a situation where the team leader onshore was absent and they were instead dealing directly with the developers at the onshore site. They mentioned:

"The project ran 10 to 12 days late, because we sent them a problem, and they sent it back to us. But if the team leader was there, it would have been completed in the first round".

No similar example was reported in the South African case.

Nevertheless, the act of restricting communication across the sites to only key individuals does not imply less frequent communication threads. On the contrary, stakeholders should still communicate frequently. It was reported by a developer in the Mauritian case study that the team leader:

“...phone them [France onshore site] everyday to give feedback. [Mauritian team leader and onshore manager] talk to each other every day and if there is a problem, they will tell us that the job is not well done and something has to be done".

Similarly, in the South African case [onshore site], the need for frequent communication was never undermined as can be seen in a statement made by one of the developers:

"...we have to communicate all the time to discuss about issues that we've had the previous day and how to overcome them".

Communication frequency should also occur among the stakeholders within the different sites. As opposed to communicating with their team members across the sites, developers instead extensively communicated among themselves and with their team leaders at their respective site. For instance, as reported by a developer in the Mauritian case study, problem solving would proceed in the following way:

"...[we] deal directly with the team leader. He will be aware of the problem. If there are any technical problems, we also call the team leader and he comes. Because we communicate a lot, there isn't any problem. We do not sit idle, so there are no delays".

In addition to frequency, some level of flexibility should also be allowed within the whole communication practice. For instance, both the Mauritian and the South African cases revealed that even though only the team leaders were officially allowed to contact the managers onshore, developers are sometimes allowed to do so, whenever specific issues needed to be addressed. For instance, in the Mauritian case, a developer stated that "if he [the team leader] is not here, and I am having some problem, then I can call". Even the team leader acknowledged that in his absence: "...if there is a problem and if the developers are blocked, they can contact the people onshore". In the South African case study, a developer offshore made a similar statement:

"...if specific answers are needed, then you can talk to the specific developer or tester working on that specific task”.

\section{Culture}

The cultural heritage seems to influence GSD in both Mauritian and South African cases. For instance, the success of the previously described communication practice (restricted communication across the sites) also appears to be dependent on the culture of the onshore and offshore site. In the organisations from the offshore sites, namely Mauritius and India, a high adaptability level seemed to prevail. Participants from both Mauritius and India identified themselves as being highly adaptable and used this cultural trait to explain why they accepted and embraced this form of communication practice. For instance, one Mauritian interviewee mentioned that: 
“... sometimes I wish that I could communicate more but I understand that it's the way that the work process has been set up and I have to abide to it. So I just adapt and follow the rule, and it works".

In turn, one Indian interviewee stated that "we [the Indian participants] adapt very much". Even the South African participants acknowledged the high adaptability level of their foreign coworkers: "They adapt more than us, I think. And it is more difficult for them than for us".

The use of restricted communication across the sites seems to be appropriate for onshore sites with hierarchical organisational cultures. In essence, if at the onshore site participants are prone to respecting organisational hierarchies, the communication will be organised in a hierarchical manner across the dispersed sites. Therefore, team members offshore are expected to communicate to their team leaders and team leaders then communicate to project managers onshore. One of the Mauritian interviewees explained:

"French people enjoy hierarchy. They respect all the hierarchical levels very seriously and you can't bypass someone to go to the manager. It's something which is not acceptable in their culture".

No similar comment was made in the South African case study.

The lack of knowledge pertaining to the offshore culture also influences effectiveness of GSD practices prescribed by past studies. For instance, in the South African case study, the use of travel and international meetings was not always successful. This GSD practice is, however, popular in the GSD literature and is recognised as an efficient one (Paasivaara, 2003). For the South African case, delegates from the South African teams were sent to the Indian offshore site but due to ignorance and fear pertaining to the Indian culture, the visit was short and inefficient. The statement made by one of the South African interviewees clearly illustrates this point:

"... a few of them were women, so their husbands were scared that they were going to get raped or going to get mutilated. Although none of that actually happened, they themselves were very scared. Even though they were staying in 5 star hotels, they used to lock all their doors and put a cabinet on the door so that nobody can come in. The previous team that went there, they never got out of the hotel. They went in the car to the hotel and in the car to the office. They stayed there 3 weeks and they never stepped out of the hotel. Eventually they could not take it anymore and they came back before the end of the mission".

Ignorance, which appears to lead to fear hence impacts on the success of the GSD prescribed practices. Therefore, it appears that some level of open-mindedness is crucial, and that stakeholders should be open to new cultures. On the other hand, for the Mauritius case study (offshore) the French offshore team had more open-minded delegates visiting Mauritius. As mentioned by an interviewee from the Mauritian case study:

"They came and they were very friendly. They trained us, and showed us how to do the job and they were very helpful. We got used to them and to their ways of doing things".

Furthermore, when some delegates from the Indian offshore team visited the South African onshore site, the visit was also successful as can be seen in this statement:

"... and then this year, we said that we're going to bring those resources [from India] to do the whole thing here, and just try out the model. And it worked out pretty well”.

It can therefore be stated that the cultural heritage as well as the level of ignorance pertaining to the other cultures impacts on the effectiveness of prescribed GSD practices. 


\section{Technology and Communication Practices}

The study reveals that a wide range of technologies are currently being employed in the Mauritian and South African GSD context. This goes in line with what was prescribed by previous GSD studies stating that a wide range of technologies should be employed across the dispersed sites (Carmel, 1999; Herring \& Rees, 2001). However, it appears that the organisations under study favoured specific technologies based on their infrastructure. When the infrastructure could support technologies requiring high communication speed, video conference was favoured. In other circumstances, the phone or emails were employed. For instance, in the Mauritian case, practitioners mostly employed the video conference tool as they did not encounter many bandwidth problems, as the following statement indicates:

"We mostly use video conference and we do not experience any delays due to lack of bandwidth"

In the South African case, video conference was not employed due to bandwidth limitations, as the following statement indicates:

"In South Africa we encounter serious bandwidth issues while talking to Belgium or the rest of the world. Sometimes, while talking to Belgium, the line goes down. So we do get communication interruptions because of bandwidth limitations in South Africa. Hence we do not use video conference"

Both cases also reveal that a wide range of technologies are employed to match specific forms of communication practices. For instance, email was used when formal communication was required, the discussion thread had to be recorded for document approval and sign-off, document sharing, agreement seeking, confirmation and clarifications. Here are some examples:

"We normally use the email for formal tasks. For instance if we are launching a new project, or if we completed a project, or if we have a recurring issue, we send emails."

"Email is generally for transfer of documentation like agenda, meeting minutes, or UML documents [technical diagrams]."

"Email is beneficial whenever you need a written confirmation on something. For example an approval on the cost."

"When we deliver the project, if there are issues, clarifications or modifications, they send us a mail officially."

"Email is very effective. We even get to a point where we get sign off for documents by email"

In the Mauritian and South African cases, the phone was employed whenever urgent tasks had to be accomplished, to quickly inform stakeholders about problems encountered during the project, to support the requirements elicitation process, and to minimise uncertainty, as the following statements indicate:

"Phone is important when there is something very urgent. For example, if there are issues which must be fixed urgently, we just phone them."

"The phone is used when we need to get an answer right away."

"During the analysis phase of the project, if we are not sure of some requirements specified in the documentation, we phone them to obtain some clarifications."

Instant messaging applications were only employed in the South African case study. These tools were found appropriate when quick responses were expected, presence awareness was required, and message tracking had to be maintained, as indicated below: 
"And I like the fact that instant messages can be saved. You can go back and look for it if you want to."

"Instant messaging is used for status updates. 'There is this kind of issue, are you fixing it?' It's just for quick feedback. It's easier than going on the phone."

"If we didn't have instant messaging, it would have made life so much difficult. I think it's one of the best communicating tool that I've used. I've got my list of contacts opened permanently and I can see whether the person's available or not."

Teleconference was often employed in both the South African and the Mauritian case study. The technology was frequently used for large projects, during the analysis and elicitation phase, to promote uncertainty minimization, and for agreement seeking procedures. Here are two examples:

"With teleconference, if you are confused while someone is explaining a concept, you can immediately stop them and you can ask your question. And when the issue is clarified, you can ask them to continue. So you can exchange ideas quickly."

"We can have a group discussion with teleconference; everyone is available and can make suggestions. Decisions are immediately taken. So if we are experiencing issues, we have a teleconference; we sit, talk, and make decisions."

A systems analyst from the Mauritian case also mentioned that project management tools improved the collaboration process across the sites, as this technology allowed information to be conveyed in different forms, project information (delivery date, testing schedule) stored, and documents managed:

"We use project a project management tool. The tool is good as it promotes collaboration as we all have access to relevant information pertaining to a project."

This implies that GSD practitioners in Mauritius and South Africa are well aware of their different communication needs, pertaining to the project type and the different project phases. The communication technology is then chosen accordingly.

Limitations inherent to the use of some technologies are circumvented by the processes followed which are derived from culture prevailing in the organisation. For instance, in the South African case delays could be encountered due to the asynchronous nature of emails were managed through clear contract negotiations and agreement seeking mechanisms which prevailed in the organisational culture, as one respondent put it:

"Email delays are not an issue. In the contract signed with the client, we ask for three-four working days to respond to email.If they do not abide to the contract, we escalate to upper management."

\section{Technology and Culture}

The results of the study also suggest that culture impacts on the choice of technology employed within the organisation. For instance, in the South African case, the organisational culture valued upfront agreement seeking and, therefore, technologies that seemed to facilitate this process were mostly employed. Here is one illustration:

"We even get to a point where we get to sign off for documents by email. If you are in agreement with what you're doing, you send an email to confirm. And then we upload everything and we attach and then store it to our project management directory"

In the Mauritian case, culture also impacted on the choice of technology. For instance, as previously explained, the organisational culture was hierarchical and only team leaders were allowed 
to communicate with the onshore team. In consequence, only team leaders had telephone lines at their desk. Here is one illustration:

"Not everyone has a phone and only the team leaders have phone lines. I don't use the phone. Only the team leaders do, as they need to contact the project managers."

Based on the case studies, it also appears that by combining the use of several technologies, cultural requirements are satisfied. Cultures that prefer formal arrangements and procedures prefer emails in combinations with tools like conference calls over other forms of communication tools. For instance, both in the Mauritian and the South African case, documents requiring approval and sign-off were sent off by emails for prior reading, and meetings were then organised and conference calls were then scheduled to discuss any potential amendments to the document. Follow some indicative statements:

"The approach is that you send a document by email and setup a conference call meeting to go through the document."

"We use the email for formal things. If we are launching a new project, completed a project and sending it off to be validated, or if we have a problem needing to be solved, we send an email. And if the mail itself is not sufficient, then we phone that person to request for more information."

The impact of culture on the choice of communication technology can also be seen in the use of instant messaging applications. The South African organisation described themselves as "easy going and informal" and hence enjoyed using instant messaging applications which they considered as being informal:

"I think chat is the most efficient... And the formality of email is gone. No-one is formal on chat. I think that's quite efficient."

In the Mauritian case study, culture impacted on the choice of technology primarily when language barriers had to be avoided. For instance, some Mauritian developers who were not very fluent in French and in expressing themselves with the correct French accent while speaking preferred the use of email over the phone. Here is one typical comment:

"If I speak with someone who speaks a bit quickly over the phone, I won't feel at ease. So I take much time in understanding. So that's why I prefer email over the phone."

It can also be noted that culture impacts on the effective use of the technology employed for communication. For instance, while using the video conference tool, the Mauritian team at times felt that the communication pace was too fast and that they could not follow the course of the conversation. Video conference offered visual connection across the sites and it could have been easy for the Mauritian team to stop the flow and probe for further information. However, due to their culture whereby interruptions were considered as rude, they did not and allowed the video conference meeting to proceed. This reduced the effectiveness of the video conference system that, under other cultural circumstances, could have been more effective. Here is an illustration of this finding:

"The main disadvantage I would say is that sometimes they go a bit fast. And it's not very polite for us to say: 'OK I did not understand this part'. Most of the time, we prefer to listen to them. It's very rare that we have immediate questions because we have to analyse the documentation to see what's happening, how should we do and proceed on, and then we take some decisions. That I would say is the main issue, it's a bit fast."

Culture impacting on the effective usage of the technology could also be seen in the use of email by the Mauritian team. Emails had to be written in French while using an English keyboard. Hence the process was not efficient. Based on the French vocabulary and grammar special char- 
acters had to be typed which could not be easily be inserted while using an English keyboard. One respondent reflected on this challenge in the following way:

"When using mail, you have big problems. It is difficult to write long emails as it is time consuming and the keyboard that we use in an English one. Since they expect us to use very formal French we have to insert the accents, and it is very difficult to do so."

In contrast, if the organisation did not share a culture where formal writing style was required, the accents could have been overlooked and the use of an English keyboard to write emails would not have been complicated.

\section{Conclusion}

The purpose of this study was to explore GSD in the South African (onshore) and Mauritian (offshore) context, to understand the various forms of communication practices and the influence of culture on GSD success. The study was performed through multiple qualitative case studies within two focal GSD organisations located in South Africa and Mauritius. The grounded theory methodology was applied to analyse the data.

The findings show that communication practice whereby one key person at all sites is responsible for communication management and coordination can be successful in both the Mauritian and South African context. The communication practice is typically successful provided that the frequency of communication within and across the dispersed sites is maintained. Some level of flexibility is also required so that people (other than the key communicant) are allowed to communicate to other dispersed sites in the absence of the coordinator or when specific answers are required. The offshore teams should also possess high adaptability to embrace the communication practice, which is also best suited to a highly hierarchical onshore culture. The other major finding of the study relates to the fact that the cultural heritage of a country as well as the level of ignorance pertaining to the other culture should be taken into consideration as it might affect the effectiveness of GSD practices. Finally, with respect to technology, the study has found that the selection of communication technologies is driven by communication and cultural needs. Culture also influences the effectiveness with which communication technologies are used.

\section{Practical Contributions}

Findings from this study might be relevant to practitioners wishing to partake in GSD in the Mauritian or the South African setting. In essence, it was demonstrated that the communication coordinator practice can be effective in the Mauritian setting and practitioners can therefore chose to embrace it if need be. The findings also inform practitioners about the need to take the special cultural heritage of South Africa into consideration when applying GSD prescribed practices in that context.

\section{Theoretical Contributions}

Numerous findings corroborate what was previously prescribed in literature. For instance, in line with Herbsleb and Grinter (1999), the two case studies reveal that early international meetings should be held to facilitate contact initiation, bridge physical distance among team members, and mitigate the disadvantages of some communication tools. In conjunction to what was prescribed by Paasivaara (2003), it appears that communication liaisons should also be sent to the dispersed sites to reduce communication issues and the negative impact of time zone difference. Furthermore, the results suggest that frequent meetings (weekly video conference, ad-hoc meetings, and emergency workshops) should also be held to reduce communication misunderstandings and bridge distance, as prescribed by Paasivaara and Lessenius (2004). It also appears that constant communication throughout the GSD project is an important factor contributing to GSD success as 
it overcomes deadline issues. This finding corroborates what was prescribed by Herbsleb, Paulish and Bass (2005). In line with Suchan and Hayzak (2001), the study also suggests that the use of one common language while communicating should also be employed as a means to provide a shared understanding of the context and to minimise communication issues due to information loss.

However, the study also identified key practices which appear to add to the body of knowledge. In essence, it was found that even through limited communication across all job titles and across all sites, GSD can be successful as time zone difference and communication issues can be mitigated. The study also uncovered that communication should, however, be carefully planned and uncertainty minimisation techniques should be employed as a means to facilitate contact initiation and improve communication process by reducing the risk of having disagreements.

Some cultural practices uncovered in this study are also in concordance to literature. For instance, in line with Jarvenpaa and Leidner (1999), Kayworth and Leidner (2000) and Sarker and Sahay (2002) the result suggest that cultural awareness programs should be held as a means to reduce the negative influence of cultural difference. It also appears that the cultural difference impact can be mitigated through the use of cultural liaisons (as seen in Carmel \& Agarwal, 2001), and technical and managerial liaisons (as seen in Heeks et al., 2001).

However, as opposed to literature, the study reveals communication practices should be employed in accordance to the cultural traits of the participants. Also, if limited interactions occur among the participants, cultural issues and misunderstandings can be avoided. The study finally contributes to theory by revealing that in spite of adopting commonly accepted GSD practices like international meetings or the use of rotation of management, these can fail if the delegates are not open-minded and well versed about the culture of their foreign colleagues.

In line with literature, the study reveals that in the absence of adequate technology, the whole GSD process would not be feasible (Dourish \& Bly, 1992; Handel \& Herbsleb, 2002; Hindus et al., 1996; Majchrak et al., 2000; Maznevski \& Chudoba, 2000 Nardi et al., 2000; Obata \& Sasaki, 1998). In particular, based on the result of the study, it can be posited that a wide range of technologies should be employed, and each tool should be suited for one specific form of communication practice or culture. As such, provided that the infrastructure is satisfactory and that the right tool is employed, the communication process should not fail and minimal issues should be encountered.

\section{References}

Adato, M., Carter, M., \& May, J. (2004). Sense in sociability? Social exclusion and persistent poverty in South Africa. Proceedings of the Conference on Combating Persistent Poverty in Africa, 15-16 November, University of Wisconsin-Madison.

Apartheid South Africa. (n.d.). History of South Africa. Retrieved April 24, 2009 from http://www.southafrica.to/history/Apartheid/apartheid.htm

Brown, I. (2005). Espoused theory versus theory in use: The case of strategic information systems planning. Unpublished PhD Dissertation, University of Cape Town.

Burton, N. (2009). ICT and business process outsourcing (BPO) in Mauritius. Retrieved April 24, 2009 from www.uneca.org/codi/codi5/content/CODI-V-ICT BPO Mauritius-Burton-EN.ppt

Carmel, E. (1999). Global software team: Collaborating across borders and time zones. New Jersey: Pearson Prentice-Hall.

Carmel, E., \& Agarwal, R. (2001). Tactical approaches for alleviating distance in global software development. IEEE Software, 18(2), 22-29. 
Casey, V., \& Richardson, I. (2006). Uncovering the reality within virtual software teams. Proceedings of the 2006 International Workshop on Global Software Development for the Practitioner, Shanghai, China.

Cockburn, H. (2002). Agile software development. Boston, MA: Addison-Wesley Professional.

Coetsee, R. (2006). Towards a theory for enterprise architecture - A South African study. Masters Thesis. University of Cape Town.

Damian, D. (2002). Workshop on global software development. Proceedings of International Conference on Software Engineering (ICSE), Orlando, Florida, USA.

Dourish, P., \& Bly, S. (1992). Portholes: Supporting awareness in a distributed work group. Proceedings of the Special Interest Group on Computer-Human Interaction (SIGCHI) Conference on Human Factors in Computing Systems, Monterey, CA, United States

Explore South Africa. (n.d.). South Africa cultures. Retrieved April 24, 2009 from http://www.exploresouthafrica.net/culture/

Fish, R. S., Kraut, R. E., \& Root, R. W. (1992). Evaluating video as a technology for informal communication. Proceedings of the Special Interest Group on Computer-Human Interaction (SIGCHI) Conference on Human Factors in Computing Systems, Monterey, CA, United States

Fiske, A. P., Kitayama, S., Markus, H. R., \& Nisbett, R. E. (1998). The cultural matrix of social psychology. In D. T. Gilbert, S. T. Fiske, \& G. Lindzay (Eds.), Handbook of social psychology. Boston, MA: McGraw Hill Education.

Guba, E. G., \& Lincoln, Y. S. (1989). Fourth generation evaluation. Newbury Park, CA: Sage Publications.

Gudykunst, W. B., \& Matsumoto, Y. (1996). Cross cultural variability of communication. In W. B. Gudykunst, S. Ting-Toomey, \& T. Nishida (Eds.), Communication in personal relationships across cultures. Thousand Oaks, CA: Sage Publications.

Handel, M., \& Herbsleb, J. D. (2002). I M Everywhere: What is chat doing in the workplace? Proceedings of the 2002 ACM Conference on Computer Supported Cooperative Work (CSCW), New Orleans, Louisiana, USA.

Heeks, R., Krishna, S., Nicholsen, S. B., \& Sahay, S. (2001). Synching or sinking: Global software outsourcing relationships. IEEE Software, 18(2), 54-60.

Herbsleb, J. D., \& Grinter, R. (1999). Architectures, coordination, and distance: Conway's law and beyond. IEEE Software, 16(5), 63-70.

Herbsleb, J. D., \& Mockus, A. (2003). An empirical study of speed and communication in globally distributed software development. IEEE Transactions on Software Engineering, 29(9), 481-494.

Herbsleb, J. D., \& Moitra, D. (2001). Global software development. IEEE Software, 18(2), 16-20.

Herbsleb, J. D., Paulish, D. J., \& Bass, M. (2005). Global software development experience from nine projects. International Workshop on Global Software Development for the Practitioner. St. Louis, Missouri, USA.

Herbsleb, J. D., Zubrow, D., Goldenson, D., Hayes, W., \& Paulk, M. (2003). Software quality and the capability maturity model. Communications of the ACM, 40(6), 30-40.

Herring, R., \& Rees, M. (2001). Internet-based collaborative software development using Microsoft tools. Proceedings of the $5^{\text {th }}$ World Multiconference on Systematics, Cybernetics and Informatics, Orlando, Florida.

Hindus, D., Ackerman, M. S., Mainwaring, S., \& Starr, B. (1996). Thunder wire: A field study of an audioonly media space. Proceedings of the Computer Supported Cooperative Work Conference, Boston, MA, United States. 
InfoPlease. (n.d.). Mauritius. Retrieved April 24, 2009 from

http://www.infoplease.com/ipa/A0107775.html

IT Match Online. (2008). Outsourcing destinations. Retrieved April 24, 2009 from http://www.itmatchonline.com/itoutsourcing destinations.php

Jaddoo, R. (2009). Mauritius Board of Investment: Mauritius: The island of opportunity. Retrieved August 21, 2009 from http://www.the-chiefexecutive.com/projects/island-of-mauritius/

Jarvenpaa, S., \& Leidner, D. E. (1998). Communication and trust in global virtual teams. Journal of Computer Mediated Communication, 3(4).

Jarvenpaa, S., \& Leidner, D. E. (1999). Communication and trust in global virtual teams. Organisation Science, 10(6), 791-815.

Kayworth, T., \& Leidner, D. (2000). The global virtual manager: A prescription for success. European Management Journal, 18(2), 183-194.

Kiel, L. (2003). Experiences in distributed development: A case study. Proceedings of the International Workshop on Global Software Development (ICSE Workshop), Portland, Oregon, USA

Knight, G. (2006). South Africa heading for economic crisis? Retrieved June 29, 2006 from http://www.oneafrikan.com/

Kogut, B., \& Meitu, A. (2000). The emergence of e-innovation: Insights from open source software development. A working Paper of the Reginald H. Jones Center, 1-32.

Kruchten, P. (2004). Analysing intercultural factors affecting global software development. Proceedings of the 3rd International Workshop on Global Software Development, co-located with ICSE, Edinburgh, Scotland.

Locke, K (2001). Grounded theory in management research. London: Sage Publications

Majchrzak, A., Rice, R., King, N., Malhotra, A., \& Ba, S. (2000). Computer-mediated inter-organisational knowledge-sharing: Insights from a virtual team innovating using a collaborative tool. Information Resources Management Journal, 13(1), 44-53.

Maturana, H., \& Varela, F. (1998). The tree of knowledge: The biological roots of human understanding. Boston: MA: Shambhala.

Mauritius.Net. (n.d.). Mauritius Info. Retrieved April 24, 2009 from http://www.mauritius.net/general_info/culture.php

Mazneski, M., \& Chudoba, K. (2000). Bridging space over time: Global virtual team dynamics and effectiveness. Organisation Science, 11(5), 473-492.

Minevich, M., \& Richter, F. (2005). Global outsourcing report 2005. Retrieved May 16, 2006 from http://www.globalequations.com/Global\%20Outsourcing\%20Report.pdf

Mockus, A., \& Herbsleb, J.D. (2001). Challenges of global software development. Proceedings of the Seventh International Software Metrics Symposium, Naperville, IL, United States

Mohagheghi, P. (2004). Global software development: Issues, solutions, and challenges, Retrieved April 07, 2009 from http://www.idi.ntnu.no/grupper/su/publ/parastoo/gsd-presentation-slides.pdf

Myers, M. D., \& Avison, D. (2002). An introduction to qualitative research in information systems. Qualitative Research in Information Systems, 4, 3-12

Nardi, B. A., Whittaker, S., \& Bradner, E. (2000). Interaction and outeraction: Instant messaging in action. Proceedings of the 2000 ACM Conference on Computer Supported Cooperative Work (CSCW), Philadelphia, Pennsylvania, United States

Nothard, P. (2000). South Africa becomes an outsourcing economy. Retrieved April 07, 2009 from http://www.itweb.co.za/office/bdsol/0008280843.htm 
Obata, A., \& Sasaki, K. (1998). Office Walker: A virtual visiting system based on proxemics. Proceedings of the 1998 ACM Conference on Computer Supported Cooperative Work (CSCW), Seattle, Washington, United States

Paasivaara, M. (2003). Communication needs, practices, and supporting structures in global interorganisational software development projects. Proceedings of the ICSE International Workshop on Global Software Development, Portland, Oregon, IEE Computer Society.

Paasivaara, M. \& Lassenius, C. (2004). Using iterative and incremental process in global software development. Proceedings of the International Workshop on Global Software Development, International Conference on Software Engineering (ICSE 2004), Edinburgh, Scotland.

Patton, M. Q. (2002). Qualitative evaluation and research methods (3rd ed.). Newbury Park, CA: Sage Publications.

Perry, D. E., Staudenmayer, N., \& Votta, L. G. (1994). People, organisations, and process improvement. IEEE Software, 11(4), 36-45.

Prikladnicki, R., Audy, J., \& Evaristo, R. (2003). Distributed software development: Toward an understanding of the relationship between project team, users and customers. Proceedings of International Conference on Enterprise Information Systems (ICEIS), Angers, France.

Ramesh, V. \& Dennis, A. R. (2002). The object-oriented team: Lessons for virtual teams from global software development. Proceedings of the 35th Hawaii International Conference on System Sciences (HICSS35), Hawaii.

Robillard, P. N. \& Robillard, M. P. (2000). Types of collaborative work in software engineering. The Journal of Systems and Software, 53(3), 219-224.

Sarker, S., \& Sahay, S. (2002). Information systems development by US-Norwegian virtual teams: Implications of time and space. Proceedings of the Thirty-Fifth Annual Hawaii International Conference on System Sciences, Hawaii.

Seaman, C. (1996). Organisational issues in software development: An empirical study of communication. Ph.D. Thesis, Computer Science Department, University of Maryland.

Shami, N. S., Bos, N., Wright, Z., Hoch, S., Kuan, K. Y., Olson, J., \& Olson, G. (2004). An experimental simulation of multi-site software development. Proceedings of the 2004 conference of the Centre for Advanced Studies on Collaborative research, Ontario, Canada.

South African languages and culture. (n.d.). Retrieved on April 24, 2009 from http://www.savenues.com/sa_languages_and_culture.htm

Statistics South Africa. (2008). Mid-year population estimate: 2008. Retrieved on July 20, 2009 from http://www.statssa.gov.za/publications/P0302/P03022008.pdf

Strauss, A. \& Corbin, J. (1998). Basics of qualitative research: Techniques and procedures for developing grounded theory. Thousand Oaks, CA: Sage Publications.

Suchan, J., \& Hayzak, G. (2001). The communication characteristics of virtual teams: A case study. IEEE Transactions on Professional Communication, 44(3), 174-186.

Tradersafrica. (n.d). Mauritius: An overview of MITCO. (n.d.). Retrieved April 24, 2009 from http://www.tradersafrica.com/articles.asp?articleid=\%7BEDE8FE1C-05C4-4D44-AA74D6D7352FA656\%7D

Van Ryssen, S. \& Hayes-Godar, S. (2000). Going international without going international: Multinational virtual teams. Journal of International Management, 6, 49-60.

Walsham, W. (2002). Interpretive case studies in IS research: Nature and method. In M. D. Myers, \& D. Avison (Eds.), Qualitative research in information systems. London: Sage Publications.

The World Factbook. (n.d.). Center for International Research, U.S. Bureau of the Census. 


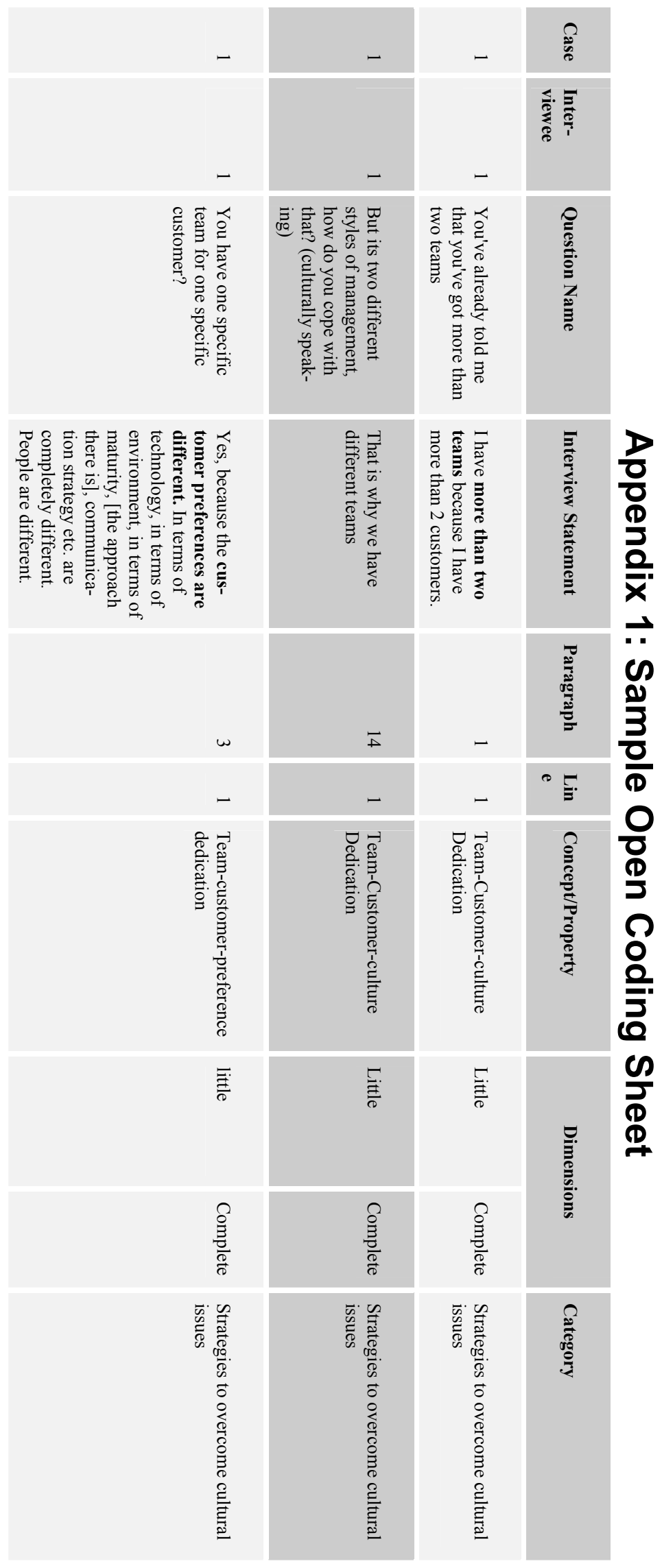




\section{Appendix 2: Sample Axial Coding Sheet}

\section{Link emanating FROM the prop- erty}

\section{Communication} style

\section{Link TOWARDS \\ the property}

Foreign language issues

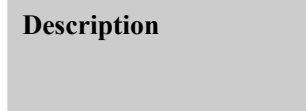

By having a formal communication style, communication issues can be reduced

Direction

\section{Interview Statement}

UP
Interview

Question

Do you think that you use some expressions that are typically from South Africa?
Hmmm... good question... I think probably not too much in kind of formal business communications. Certainly you'll have the guys out here talking about the things like robot and [...]

\section{Appendix 3: Category Listing}

\begin{tabular}{|c|c|c|}
\hline Meta-Category & Category & Concept / Property \\
\hline \multirow{19}{*}{$\begin{array}{l}\text { Communication } \\
\text { Practices }\end{array}$} & \multirow{5}{*}{$\begin{array}{l}\text { Communication among } \\
\text { team members }\end{array}$} & Communication need [Random Phases -Specific Phases] \\
\hline & & Ease of contact initiation [Easy-Difficult] \\
\hline & & Employees physical proximity [ Different countries - Same Room] \\
\hline & & Number of communicants [2 - Unlimited] \\
\hline & & Physical encounters among teams [Never - Frequent $]$ \\
\hline & \multirow{5}{*}{$\begin{array}{l}\text { Communication channel } \\
\text { description }\end{array}$} & Communication channel $[$ Dry - Warm $]$ \\
\hline & & Communication level [Minimal - Constant] \\
\hline & & Communication style [Informal - High Business Style] \\
\hline & & $\begin{array}{l}\text { Information filter through [Completely wrong Information filtered through-Cor- } \\
\text { rect information filtered through] }\end{array}$ \\
\hline & & News type $[$ Good - Bad] \\
\hline & \multirow[t]{3}{*}{ Communication facilitators } & Flexi-time implementation level [Minimal flexi-time - Maximum flexi-time] \\
\hline & & Foreign worker establishment [Permanently - Temporarily] \\
\hline & & Physical encounters importance [Not important - Really important] \\
\hline & \multirow[t]{4}{*}{ Communication strategy } & Common language [Different language used - Common language used] \\
\hline & & Communication planning [No planned communication - Planned communication] \\
\hline & & Email response time $[1$ hour -5 days $]$ \\
\hline & & $\begin{array}{l}\text { Team-customer-communication strategy [Contact with external customer allowed } \\
\text { - contact with external customer not allowed] }\end{array}$ \\
\hline & \multirow{2}{*}{$\begin{array}{l}\text { Cues transmission com- } \\
\text { munication }\end{array}$} & Perception of efforts [No perception of efforts - Complete perception of efforts] \\
\hline & & Reassurance level [Little - High amount $]$ \\
\hline \multirow[t]{5}{*}{ Culture } & \multirow[t]{2}{*}{ Individual culture } & Individual culture description [Minimal characteristics - Strong characteristics] \\
\hline & & Individual culture prevalence level [Minimal-Maximal] \\
\hline & National culture & National cultural prevalence level [No prevalence - High level of prevalence] \\
\hline & \multirow[t]{2}{*}{ Organisational culture } & Organisational culture prevalence level [No prevalence - High level of prevalence] \\
\hline & & Organisational values [Not influenced by - Highly influenced by] \\
\hline
\end{tabular}




\begin{tabular}{|c|c|c|}
\hline Meta-Category & Category & Concept / Property \\
\hline & Cultural issues & $\begin{array}{l}\text { Cultural difference impact [Little amount of cultural issues - High amount of cul- } \\
\text { tural issues] }\end{array}$ \\
\hline \multirow[t]{20}{*}{ Technology } & \multirow[t]{5}{*}{ Chat } & Feedback time [Very slow - Very fast $]$ \\
\hline & & Formality level [Informal - Formal] \\
\hline & & Frequency of use [Very rarely - Very often] \\
\hline & & Task-technology structure fit [Low fit - High level of fit] \\
\hline & & Tool efficiency $[$ Low - Excellent $]$ \\
\hline & \multirow[t]{8}{*}{ Email } & Cues transmission [Little - High amount $]$ \\
\hline & & Effectiveness level [Low - High] \\
\hline & & Tool efficiency [Low - Excellent $]$ \\
\hline & & Feedback time $[$ Very slow - Very fast $]$ \\
\hline & & Formality level [Informal - Formal] \\
\hline & & Frequency of use [Very rarely - Very often] \\
\hline & & Task-technology structure fit [Low fit - High level of fit] \\
\hline & & Tool disadvantage [Minimal - Maximal $]$ \\
\hline & \multirow[t]{3}{*}{ Infrastructure } & Infrastructure setup [Minimal setup - Excellent setup] \\
\hline & & Connection speed [Very bad - Very good] \\
\hline & & Infrastructure difference [Similar infrastructure - Different infrastructure] \\
\hline & Project Management Tool & Task-technology structure fit [Low fit - High level of fit $]$ \\
\hline & \multirow[t]{3}{*}{ Net Meeting } & Demonstration ability [Inability to demonstrate - High ability to demonstrate] \\
\hline & & Frequency of use [Very rarely - Very often] \\
\hline & & Task-technology structure fit [Low fit - High level of fit] \\
\hline
\end{tabular}

\section{Biography}

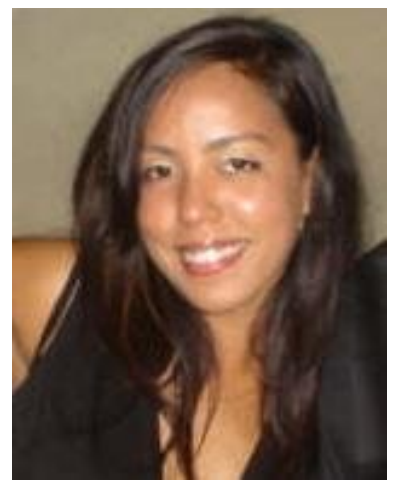

Maureen Tanner, MCom: Maureen is a $\mathrm{PhD}$ associate and Lecturer in the Department of Information Systems, University of Cape Town, South Africa. Her research interests include Global Software Development, Agile Methods, and the application of Agile Methods in the distributed software development setting. 